\title{
The missing pieces
}

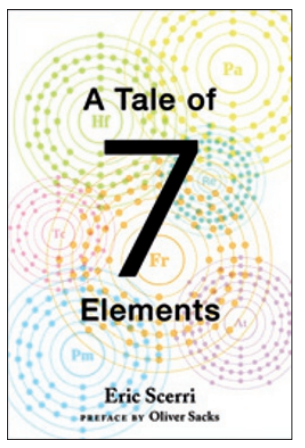

A Tale of 7

Elements

by Eric Scerri

OXFORD UNIVERSITY

PRESS: 2013. 270PP.

$E 12.99$

t's a tale every young chemist is told: once

Mendeleev had invented the periodic

table, he used it to identify missing

elements and predict their properties.

Over the decades that followed, many of his predictions proved to be remarkably accurate and served as a guide to subsequent research. This achievement of predictive science has few equals that come readily to mind.

Of course, this is oversimplification to the point of falsehood. In A Tale of 7 Elements, Eric Scerri complicates the story once more as he recounts the discovery of some of the elements that Mendeleev predicted - and some that he missed. We are treated to histories of the final seven infrauranium elements - a term Scerri introduces to mean those with an atomic number less than uranium - to be discovered: protactinium, hafnium, rhenium, technetium, francium, astatine and promethium. The first two chapters document the development of the periodic table throughout the nineteenth century and the contributions made by physics in the early twentieth century. Although these chapters are condensed excerpts from Scerri's earlier book, The Periodic Table, they provide vital context for the chapters that follow: one chapter for each of the seven titular elements and a concluding chapter that covers the synthesis of transuranium elements in the past seventy years.

The early chapters seem intended to caution the reader against naive views of the history of science, particularly the idea that the discovery of an element (or indeed, the periodic table) is an isolated, ideal event that can be pinpointed to one experiment carried out by one person. Scerri is careful to depict data as theory-laden, events and people as part of a wider context and community, and uncertainty as a constant for scientists. As a result, the key question throughout the book is that of priority: who discovered each element? What does it mean to have discovered an element? How do we determine, retrospectively, who deserves credit?

Although the philosophical and scientific responses to this question are addressed, more human factors invariably play a role even into the present day. Most notable is nationalism: the seven elements were each discovered in the context of the world wars, dividing contemporary scientists along patriotic lines. Modern readers may be surprised by how blatant some of these examples are, such as the declaration by the editor of Chemical News that "We adhere to the original word celtium given to it [element 72] by Urbain as a representative of the great French nation which was loyal to us throughout the war. We do not accept the name which was given it by the Danes who only pocketed the spoils of war."

Perhaps the greatest strength of the book is that Scerri is not a passive chronicler of history but an active and critical voice. Rather than merely recount opposing claims for priority, he examines them in detail and comes to firm and wellsupported conclusions. He considers the question of why these scientists made and defended false claims, his answers ranging from simple experimental error or optimistic interpretation to pathological science and ubiquitous nationalism. Throughout the book we are reminded that identifying which elements were missing and confirming that a claimed discovery was real were not trivial tasks, even in principle.

This makes it all the more confusing that Scerri is quick to claim nationalistic pride on the part of those with whom he disagrees in more recent priority disputes. A substantial passage is dedicated to the question of how successfully Bohr predicted the existence and properties of hafnium. This is a topic on which Scerri has published original research and he recounts a debate with the Danish historian Helge Kragh on the subject. After outlining their reasonable disagreement, he observes that their different scientific interests (Scerri a chemist, Kragh a physicist) may account for their differing interpretations of the past - and then adds a footnote that seems to accuse Kragh of defending Bohr owing to their shared nationality. In the case of Japanese chemist Kenji Yoshihara's much weaker claim for a Japanese discovery of rhenium, six pages are dedicated to demolishing his argument with the unmistakable insinuation that his motivation is national pride, rather than academic conviction. Given the thoughtfulness and nuance of the rest of the book and its emphasis on the philosophical, historical, and scientific uncertainty of the subject matter, it is rather jarring to see the implication that reasonable people cannot disagree or simply be wrong without having questionable motivations.

This unfortunate tendency does not otherwise undermine the book. The chapters each stand alone to some degree, given the partial overlap in content, and one could probably read them in any order. Although this does weaken the sense of narrative through the book as a whole, it makes each chapter readily approachable without reference to earlier sections.

\section{What does it mean to have discovered an element? How do we determine, retrospectively, who deserves credit?}

Overall, the book is both scholarly and accessible. Scerri draws on diverse fields to paint a thorough and nuanced picture of the history of the periodic table and the discovery of elements in the twentieth century in a book that is as much about the process of science as it is about the science itself. Like the best of Stephen Jay Gould's popular writing, the subject matter is explained clearly and lucidly without scrimping on the detail; a lay reader would emerge with a decent grounding in basic atomic theory. Students in particular would benefit from reading $A$ Tale of 7 Elements, as it ought to dispel any simple idealism about chemistry and, hopefully, replace it with a strong sense of context and innumerable questions.

\section{REVIEWED BY ANDREW BISSETTE}

Andrew Bissette is a DPhil student in Oxford, UK. In his spare time, he blogs at http://behindnmrlines. blogspot.com 